\title{
Intervention with Muslim Filipino Families: The Implications of Spirituality for Psychology
}

\author{
Ronald Hall \\ Michigan State University, School of Social Work, Michigan, American. \\ Email: hallr@msu.edu \\ Received January $13^{\text {th }}$, 2010; revised January $19^{\text {th }}$, 2010; accepted January $20^{\text {th }}, 2010$.
}

\begin{abstract}
Political repercussions following destructive events of September 11, 2001 have the potential to dampen enthusiasm for the incorporation of spirituality by psychologists who see Muslim Filipino families. Among various Muslim Filipino populations, spirituality is fundamental. Psychologists who are conscientious would be remiss to exclude such a critical aspect of life when it is essential. The implications of spirituality for psychology intervention with Muslim Filipino families include the need to acknowledge and, when appropriate, apply values, belief systems, and other culture specific criteria. To do otherwise will bias intervention with Muslim Filipino families, rendering psychology less potent in its ability to accommodate such families.
\end{abstract}

Keywords: Islam, Spirituality, Filipinos, Muslims

\section{Introduction}

Following the interest generated by September 11, 2001, also known as 9/11, it has become apparent that spirituality is critical to intervention with Muslim Filipino families [1]. Documentation and anecdotal accounts of Muslim Filipino spirituality offer considerable evidence to substantiate that claim. Following terrorist destruction in New York City and Washington D.C., political pundits of every type have found solace in renewed appreciation for patriotism and calls to military action. Amid such fervor, psychology intervention will require a more comprehensive approach to Muslim Filipino families. Such an approach is compulsory if psychology is to remain viable and loyal to its code of ethics [2]. Furthermore, despite the events in New York and Washington, including commercial aircraft being used as missiles to assault nonmilitary targets, psychology is not unaffected. In the aftermath of these violent events is a concern for psychologists' ability to conduct ethical and effective intervention with an increasing Muslim Filipino population. Failure on the part of psychologists will also exacerbate political repercussions and reflect negatively on the profession.

Political repercussions resulting from the events of 9/11 can potentially dampen enthusiasm for the incorporation of spirituality into psychology. Such dampening effects will disserve intervention with Muslim Filipino families who may find themselves subjected to the aus- pices of Christian and/or non-Muslim service providers. Without exception, the incorporation of spirituality is a necessity of intervention for well-meaning psychologists who may lack either the knowledge or motivation to apply it [3]. Thus, within society-despite rhetoric to the contrary-spirituality for Muslim Filipino families is a prerequisite to therapeutic services. Although professional literature acknowledges spirituality among the list of resources, amidst the prioritization of more traditional social issues it has been all but trivialized [4]. A greater focus on the significance of spirituality would enable psychologists to intervene on behalf of Muslim Filipino families efficiently and without incident. Instead, psychology has relied too heavily upon non-spiritual techniques or polite circumvention in reference to terrorism. As a result, rather than asking how they might incorporate spirituality with Muslim Filipino families, psychologists pose nebulous questions such as: "What are the deficits of Muslim Filipino families?” or "In what ways can Muslim Filipino families adjust to the Christian traditions as the Filipino cultural ideal?”

Conscientious psychologists would be remiss to exclude a critical aspect of life from intervention when it is essential. Spirituality may enhance the therapeutic potential of family values, family belief systems, and family traditions that are otherwise inaccessible by non-sectarian, non-spiritual methods. Furthermore, spirituality for Muslim Filipino families may contain coping mechanisms 
that enable them to confront and overcome the many challenges of daily life. In an effort to educate and contribute to the effectiveness of psychology with Muslim Filipino families, this paper has three objectives: 1) to provide a beginning introduction to history of the Muslim Filipino population; 2) to provide a brief definitive account of spirituality; and 3) to detail the implications of spirituality for intervention with Muslim Filipino families.

\section{History of the Muslim Filipino Population}

Muslim Filipinos represent approximately 5\% of the Philippine population [5]. As such they are the most significant minority in the nation. Racially they are of predominantly Asian descent and cannot be differentiated from the mainstream population aside from their religious traditions. In the 1970s aftermath of political turmoil the Muslim Filipino population known as Moro increasingly identified with the Muslim communities around the world including Malaysia, Indonesia, Libya, and the various Middle Eastern countries. Tensions between Muslim Filipinos and the Christian mainstream have been tenacious based upon economic neglect and societal prejudice against them.

Muslim Filipinos for the most part reside in the southern and western area of the Philippines consisting of Mindanao, Palawan, and the Sulu Archipelago. Within these Muslim Filipino communities exists ten subgroups which are distinguishable by language. Three such groups comprise the majority of Moros. They include the Maguindanaos who reside in North Cotabato, Sultan Kudarat, and Maguindanao provinces. The Maranaos are of the two Lanao provinces while the Tausugs are for the most part from Jolo Island. Lesser numbers are the Samals and Bajaus who reside on the Sulu Archipelago; the Yakans of Zamboanga del Sur Province; the Ilanons and Sangirs of Southern Mindanao Region; the Melabugnans of southern Palawan; and the Jama Mapuns of the smaller Cagayan Islands.

Historically unlike Muslims in other areas Muslim Filipinos have been less allied with one another preferring instead to emphasize their separate identities which has facilitated years of subgroup conflict. Not only do Muslim Filipinos differ by language etc. but additionally by political structures and Islamic traditions. The Tausugs for example were the first Muslim Filipinos who have criticized the Yakan and Bajau peoples for not being true Muslims. Such criticisms were eventually subjugated by a shared historical experience relative to culture, social traditions, and legal practices.

The ultimate authority figure in the Muslim Filipino community is the sultan. The sultan by tradition is considered both a secular and a religious figure whose power was validated by the Koran. Perhaps more important to daily operation of the community was the datu. Their power was measured not by their material wealth but by the size of their religious community. Tasks associated with their authority included the provision of assistance during emergencies and resolving disputes. Thus, by tradition the datu was critical to the overall functioning of the Moro community. The power of the datu might account for numerous wives and the ability to enslave others defeated in war or for debts owed. What's more if insulted a datu might demand the death of a perpetrator or the life of another as compensation for the death of one of his followers.

By the 1980s the datu remained the source of power in the Muslim Filipino community. On occasion they continue to administer the sharia known as the sacred Islamic law. While the expansion of their followers by raiding other villages is no longer possible they accomplished the same feat economically by providing assistance, employment, and protection needed by less able neighbors. Similarly in order for government programs to function properly required datu support in Muslim communities. While the datu today is unlikely to have more than one wife he is still permitted to do so if warranted by wealth. Thus the Muslim Filipino community remains hierarchical and dedicated to family particularly in rural areas.

Policies adopted post 1946 when the Philippines became independent of the U.S. are not irrelevant to tensions among Filipino subgroups. The Philippines remains a Christian nation. Under U.S. management, there existed the Bureau for Non-Christian Tribes which was abolished. The Bureau for Non-Christian Tribes dealt with minorities and promoted movement of Filipinos from heavily populated areas such as Central Luzon to relocate to the more "open" areas of Mindanao. Subsequently hundreds of thousands of Ilongos, Ilocanos, and Tagalogs began relocating to North Cotabato and South Cotabato and Lanao del Norte and Lanao del Sur provinces by the 1950s. Their relocation created resentments on the part of Moro people who were Muslims. Much of the tensions were verbalized as land disputes but not irrelevant to Christian versus Islam. To restore order Philippine army troops were sent into the area. The troops were for the most part Christians which Muslim Filipinos felt that they were unfairly at their mercy. Martial law was declared in 1972 at which time Muslim Mindano was in chaos.

Eventually the Philippine government recognized a need for structure to manage Muslim existence within a predominantly Christian country. It created the Commission for National Integration in 1957. It was later substituted by the Office of Muslim Affairs and Cultural Communities. The optimistic sought a country made up of Christians and Muslims who would be totally assimilated into the dominant Filipino culture. Their only differences would be religious preference and the refusal of Muslims to consume pork. This proposal was not acceptable to Muslims or Christians despite that the gov- 
ernment was willing to make concessions for religious customs. For example Muslims were exempted from Christian Philippine laws which denied polygamy. All attempts seemed destined to fail. In 1990 the government cooperated in the Autonomous Region in Muslim Mindanao. This allowed Muslims in the area to assume control over specific areas of government absent national security and foreign affairs.

By the 1990s there were social dynamics which impacted the ability of Muslim leaders to oppose assimilation. Economic factors contributed to increased migration of residents from the region which introduced new roles and educational opportunities for women. These resulting interactions between Christians and Muslims led to more opportunities for assimilation and eventually intermarriage [5]. Despite the fact, Muslim Filipinos remain distinct by religious and cultural traditions which will require any psychologist be knowledgeable of their spirituality subsequent to intervention.

\section{Spirituality}

Among the various Muslim Filipino populations, spirituality is fundamental. Any attempts on the part of psychologists to define the concept of "spirituality" will be fraught with formidable challenges. However, an appropriate genesis is contained in the root words for "spirit." In Latin the term, spiritus conveys breath, courage, vigor, or life. According to Philip Sheldrake [6], spiritus was an effort to translate a Greek noun pneuma into English and which appeared in the Pauline letters of the Holy Bible. Similar to its Hebrew counterpart, ruach, pneuma means "wind," "breath," "life," and "spirit" $[7,8]$. The fact that "spirit" is so intimately associated with life is reflected in a definition of the Tenth Edition of Webster's Collegiate Dictionary [9]: "an animating or vital principle held to give life to physical organisms" (p. 1134). While the term "spirit" implies physical vitality in "breath," it is in fact essential to much more than respiration. According to Rudolph Otto [10], "spirit" also pertains to "the holy.” In such a context, "spirituality" refers to the human search for purpose and meaning in life. Much to the dismay of some, the aforementioned concept of "spirituality" does not necessarily pertain to the existence of a Supreme Being or a higher source of power.

Numerous scholars have attempted to define spirituality in an effort to simplify its myriad complexity of meanings. Among those are Joseph M. Cervantes and Oscar Ramirez [11], who suggests that spirituality includes the pursuit of universal accord and completeness. Paul Tillich [12] maintains that spirituality pertains to humanity's utmost concerns relative to the meaninggiving aspect of culture. Father Leo Booth [13], in a more tangible explanation, refers to spirituality as an "inner attitude that emphasizes energy, creative choice, and a powerful force for living” [13]. Similarly, Elkins, Hed- strom, Hughes, Leaf, and Saunders [14] suggest that spirituality included an admiration for the holiness of life and a harmonious regard for the material, an attitude of altruism toward one's fellow man, hope for a better world, and the acknowledgement that life has a tragic dimension. Furthermore, according to Chandler, Holden, and Kolander [15], spirituality includes "any experience of transcendence of one's former frame of reference that results in greater knowledge and love." Subsequently, Hinterkopf [16] refers to spirituality as something felt in one's body. Such a feeling then precipitates comprehension of new meanings in life which enhances growth. Finally, Holifield [17] contends that spirituality is "less a method than an attitude, a posture of one's very being that allows seeing not different things but everything differently" [17]. However spirituality is defined, intervention with Muslim Filipino families necessitates that psychologists be informed of the implications for intervention.

\section{Implications of Spirituality for Intervention}

The implications of spirituality for psychology intervention include the need for practitioners to acknowledge and, when appropriate, to apply values, belief systems, and other culturally specific criteria. This will provide the psychologist with alternatives to bring about desired changes or coping-mechanisms. It is not compulsory that psychologists endorse client belief systems or other aspects of spirituality, but they should acknowledge such systems as critical to the client's frame of reference.

Especially among Muslim Filipino families where Islam is the spiritual tradition, reverence for the patriarch, as well as concern for the family's status, provides a strong sense of solidarity and loyalty [18]. Hence, psychologists must know that individual family members are not free to live independently, but are required to consider family in each of their life decisions as prescribed by the Koran. The Koran, being the direct instruction from God, means that family members are expected to fulfill rules of behavior, family roles such as husband, wife, child, and so forth without the opportunity for personal input or preference. An individual's ability to adhere to spiritual directives reflects not so much upon him or her personally but upon the family and its kinship network. In the Islamic patriarchal tradition, males are more valued than females, which may cause conflict in Christian Filipino settings. However, unless influenced by such traditional Filipino norms, anxiety levels from this secondary status may not increase for women of Muslim Filipino families.

The importance of spirituality among Muslim Filipino families is evident in the extreme reluctance of individuals to yield to conversion [18]. Twentieth-century Christian missionaries are well aware of this reluctance. The number of Muslim Filipino believers who have converted from Islam to Christianity is very small. For the individ- 
ual Muslim Filipino, family is not irrelevant to that small number, as the family role in the existence of the community is crucial. Accordingly, Muslim Filipino families who migrate to the U.S. or elsewhere often send for their "old country" relatives. Once abroad, there are few who do not have blood ties. Those who do are obvious by their difficulty in finding jobs or otherwise sustaining themselves. Frustrated, such Filipinos, without family, frequently return to the Philippines where normal family ties are a way of life. This significance of family is evident by the fact that whole Muslim Filipino communities may contain a small number of patrilineages [18]. Consequently, there is considerable overlap between family and spirituality within the Muslim Filipino community. However, while family is an important social structure, spirituality as it pertains to Islam, guides life and the family belief system. Psychologists who do not acknowledge this will be at a severe disadvantage in their attempts to intervene on behalf of Muslim Filipino clientele. Those who understand this structure will consider the values extended from spirituality when working with Muslim Filipino families. Values that are recognized by the Koran include: Hospitality and generosity in giving and spending; Respect for elders and parents; Wealth and male children; Subordination of women to men; Modesty; Intensive religiosity; Equality of all human beings; and Health and strength [18].

Psychologists who serve Muslim Filipino families should cultivate working relationships with Islamic clergy which is as critical as understanding spirituality. These relationships will prove useful in the clarification of Muslim Filipino norms, the facilitation of referrals, and the effective application of intervention strategies. Such relationships are mutually beneficial to the extent that both community and psychologists are enabled by the information that is exchanged. While some Muslim Filipino families may prefer assistance from Islamic personnel, others may be uncomfortable or self-conscious about expressing family concerns to Islamic members of a tight-knit community. Under such circumstances, the availability of psychologists might prove invaluable. What is more, the availability of psychologists will be particularly helpful if in fact the spiritual system (Islam) is the focus of the client's dysfunction. The professional psychologist will allow the client to explore spiritual alternatives within the context of a spiritually neutral clinical environment.

\section{Conclusions}

From the perspective of the psychologist, there are several reasons why they might consider the incorporation of spirituality with Muslim Filipino families. First, the effects of spirituality are well known and are likely to enable intervention with such families [19]. Secondly, the term "spirituality," for psychologists, conjures up images of legal conflicts with the potential to charge emotions; when associated with stereotypes the term encourages knee-jerk condemnation of an entire religious group, their social structure, lifestyle, and other aspects of their being [20]. The outcome may impair the ability of such groups to sustain them in the human social environment unless more rational factions prevail. Thirdly, spirituality must be viewed separate and apart from the legal process. To do otherwise will bias intervention with Muslim Filipino families, thus rendering psychology less potent in its ability to accommodate said families.

Beyond legal conflicts, the most efficient means of enabling intervention with Muslim Filipino families is for psychologists to become more educated about Islam as pertains to Muslim Filipino spirituality. Education pertaining to spirituality and Islam together will enable intervention [21]. Psychologists who are so enabled will be in a better position to learn and assist Muslim Filipino families in sustaining themselves. Furthermore, psychologists who help reinforce respect for Muslim Filipino populations build the self-esteem of younger family members, which will assist the group's ability to survive as a whole. Equally important is the impact, on Filipino society at-large, of being informed of spirituality. One approach to being informed is to create tolerant environments by the building of bridges to Muslim Filipino communities, bridges beyond what is professionally necessary. The focus should be on cultural traditions, rather than on terrorist acts associated with any one of its member(s). Community action groups and youth projects, which familiarize the otherwise unfamiliar, have the potential to validate psychology as a helpful profession among Muslim Filipino families who might not otherwise seek intervention services [22].

Due to the potential for harm and legal repercussions brought by spirituality, it is critical that psychologists exercise caution when incorporating spirituality into their work. From a traditional Christian Filipino perspective, some aspects of Islam and other manifestations of spirituality might appear abnormal and indeed dysfunctional. For example, among certain Christian sects is the phenomenon of "speaking in tongues," where church-goers slip into a trance-like state and begin to verbalize in an unfamiliar language [23]. In the not too distant past, such persons may have been diagnosed as psychotic and received prescriptions for psychotropic medication. In fact, among these Christian sects, speaking in tongues is not regarded as psychotic or abnormal. Indeed, it is perceived by them as a gift from God. Thus, for legal as well as practice reasons, psychologists must resist the inclination to label spiritual phenomena simply because it is unfamiliar and/or not Christian in origin. Furthermore, psychologists who serve Muslim Filipino families must also be cognizant of their own belief systems and what that conveys to the client [23]. The psychologist's position on 
spirituality is not irrelevant to setting the tone of the practice environment [23]. From those who endorse spirituality to those who reject it, there will be an impact in a myriad of ways.

Lastly, the ability of Christian Filipino psychologists to accurately perceive, conceptualize, and interact with Muslim Filipino families is a necessity in a rapidly changing and complex world. In order to enhance harmony and reduce the threats of terrorism, psychologists and other concerned citizens must acknowledge that all groups have assets, capacities, and strengths that should be reinforced despite the heinous acts committed by a relative few [24]. Since many of these assets such as cultural technologies are derived from cultural legacies, psychologists must increase their knowledge base considerably. Otherwise, their lack of education could contribute to the extinction of an irreplaceable Filipino component of mankind, which might prove antidotal to violence and terrorism worldwide. Furthermore, at a time of increased contacts between the world's various populations, psychologists are confronted by issues and perspectives that did not require intellectual consideration in the past [25]. They are thus challenged to develop creative strategies less confined to bias. Additionally, journal editors, book publishers and other affiliates of the "fact" manufacture industry must be actively receptive to the consideration of alternative views. That consideration must remain consistent and viable without interruption from unpredictable events to sustain the integrity and prestige of the psychology profession.

\section{REFERENCES}

[1] S. Crabtree, "Culture, Gender and the Influence of Social Change amongst Emirati Families in the United Muslim Filipino Emirates," Journal of Comparative Family Studies, Vol. 38, No. 4, 2007, pp. 575-587.

[2] G. Koocher and P. Keith-Spiegel, "Ethics in Psychology," Oxford University Press, New York 1991.

[3] D. Hodge, "The Spiritually Committed: An Examination of the Staff at Faith-Based Substance Abuse Providers," Social Work and Christianity, Vol. 27, No. 2, 2000, pp. 150-167.

[4] K. Callaghan and F. Schnell, "Who Says what to whom: Why Messengers and Citizens Beliefs Matter in Social Policy Framing,” Social Science Journal, Vol. 46, No. 1, 2009, pp. 12-28.

[5] R. Dolan, Ed., "Philippines: A Country Study,” GPO for Library of Congress, Washington, D.C., 1991.

[6] P. Sheldrake, "Spirituality and History: Questions of Interpretation and Method,” Crossroad, New York, 1992.

[7] R. Delbane and H. Montgomery, "The Breath of Life: Discovering Your Breath Prayer," Harper and Row, San Francisco, 1981.
[8] N. Roth, "The Breath of God: An Approach to Prayer," Cowley, Cambridge, 1990.

[9] Merriam-Webster, Inc., "Webster's Tenth Collegiate Dictionary,” Springfield, Merriam-Webster, 1993.

[10] R. Otto, “The Idea of the Holy," Vintage Books, New York, 1958.

[11] J. M. Cervantes and O. Ramirez, "Spirituality and Family Dynamics in Psychotherapy with Latino Children," In L. A. Vargas and J. D. Koss-Chioino, Eds., Working with culture: Psychotherapeutic Interventions with Ethnic Minority Children and Adolescents, Jossey-Bass, San Francisco, 1992, pp. 103-128.

[12] P. Tillich, “Theology of Culture,” Oxford University Press, New York, 1959.

[13] L. Booth, “The Stages of Religious Addiction," Creation Spirituality, Vol. 8, No. 4, 1992, pp. 22-25.

[14] D. Elkins, L. Hedstrom, L. Hughes, J. Leaf and C. Saunders, "Toward a Humanistic Phenomenological Spirituality,” Journal of Humanistic Psychology, Vol. 28, 1988, pp. 5-18.

[15] C. Chandler, J. Holden and C. Kolander, "Counseling for Spiritual Wellness: Theory and Practice,” Journal of Counseling and Development, Vol. 71, 1992, pp. 168-175.

[16] E. Hinterkopf, "Integrating Spiritual Experiences in Counseling," Counseling and Values, Vol. 38, 1994, pp. 165175.

[17] E. Holifield, "A History of Pastoral Care in America," Abingdon, Nashville, 1983.

[18] A. Wasfi, "Dearborn Muslim Filipino-Moslem Community: A Study of Acculturation," Ph.D. Dissertation, Michigan State University, East Lansing, 1964.

[19] I. Mattson, "Discovering the Spirituality of Muslim Women,” Zion's Herald, Vol. 179, No. 4, 2005, pp. 3536.

[20] D. Bar-Tal and D. Labin, “The Effects of a Major Event on Stereotyping: Terrorist Attacks in Israel and Israeli Adolescents' Perceptions of Palestinians, Jordanians and Muslim Filipinos,” European Journal of Social Psychology, Vol. 31, No. 3, 2001, pp. 265-280.

[21] A. Al-Krenawi and J. Graham, "Culturally Sensitive Social Work Practice with Muslim Filipino Clients in Mental Health Settings," Health and Social Work, Vol. 25, No. 1, 2000, pp. 9-22.

[22] B. Santamour, “A Mission to Listen,” Hospitals and Health Networks, Vol. 81, No. 4, 2007, pp. 34-38.

[23] M. Gilbert, "Spirituality in Social Work Groups: Practitioners Speak Out," Social Work with Groups, Vol. 22, No. 4, 2000, pp. 67-84.

[24] D. Sontag, "As Emotions Boil Over, Muslim Filipino-Israeli Violence Rages On,” New York Times, 20 May 2001, p. 4.

[25] A. Shatz, “The Doctor Prescribed Violence," New York Times, 2 September 2001, p. 11. 